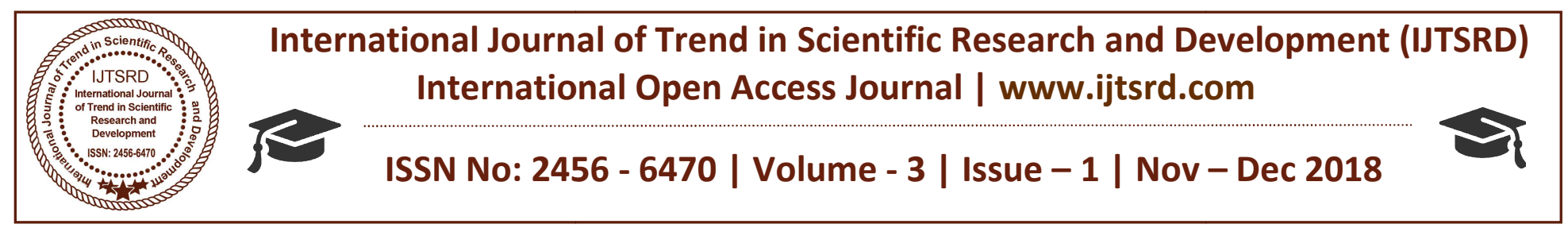

\title{
Interfacing and Interconnection of Microgrid Systems: A Review
}

\author{
Ajaz UI Haq \\ M.Tech Scholar, Electrical Engineering Department \\ YIET, Gadhauli, Yamunanagar, Haryana, India
}

\begin{abstract}
A microgrid is mostly a portion of the power distribution system that includes distributed generation, energy storage and loads. To be accomplished of working in parallel to the grid, as an independent power island and in transition modes, microgrids must be vigorous in governing the local voltage and frequency, and shielding the network and equipment connected to the microgrid. It also necessities to ease demand side management and resynchronization. This paper presents a review of existing microgrid test networks around the world and some significantly different microgrid simulation networks present in the literature. Paper is focused on the test systems and available microgrid control options. A summary table comparing and contrasting the existing test systems is presented. The paper is concluded highlighting the worthy findings and possible areas of research that would enhance practical use of microgrid facilities.
\end{abstract}

\section{INTRODUCTION}

Microgrids are emerging as an integral feature of the future power systems shaped by the various smartgrid initiatives. A microgrid is formed by integrating loads, distributed generators (DG) and energy storage devices. Microgrids can operate in parallel with the grid, as an autonomous power island or in transition between grid-connected mode and islanded mode of operation.

A microgrid could be an attractive option to harness the benefits offered by distributed generation, eliminating the constraints on high penetration. Thus, substantial environmental benefits may be gained through the utilization of energy efficient generation resources and the integration of renewable energy resources. Moreover, microgrids could reduce the network losses, defer the high investment costs required for network upgrades and also reduce the central generation reserve requirements. DGs provide local voltage support and microgrid as a whole increases the overall system reliability [1], [2], [3], $[4],[5],[6]$.

This paper reviews the current status of the development of microgrids. This will cover a brief description on components of a microgrid and a literature review on existing microgrid test systems that have been implemented and simulated. The paper contributes as a particularly focused resource, which consolidates existing microgrid research experiences in an corganized structure. It guides the reader to visualize the present big picture of the microgrid and allows understanding the potential developments. Furthermore, the comparison of microgrids in several continents provides useful information for the design and choosing the right features for a particular microgrid application. It is also envisaged that the information summarized in the paper contributes to open research beyond the existing trends.

\section{The Picture of a Microgrid}

A microgrid is encompassed of variety of distributed generators (DG), distributed storages (DS) and variety of customer loads. It is particularly a portion of an electric power distribution system located downstream of the distribution substation. Thus, the microgrid point-of-common-coupling (PCC) lies at the vicinity of the low voltage side of the substation transformer.

\subsection{Distributed Generators}

Generation technologies applicable for a microgrid may include emerging technologies (Combined heat and power (CHP), fuel cells, mini wind turbines, PV, micro-turbines) and some well established generation technologies (single-phase and three-phase induction generators, synchronous generators driven by IC 
engines or small hydro). These generation technologies are well known [1], [2] and thus, it is not discussed in detail in this paper. Nevertheless, it is important to note that CHP (also known as cogeneration, which produce electricity and heat simultaneously) and wind power generation has shown considerable growth in technology and usage gaining strong points to be used in microgrids.

Almost all large integrated power systems in the world have been relying on centralized electricity generation such as large-scale hydro, coal, natural gas and nuclear power plants. Long-distance, high-voltage transmission carried the power to the customers from centralized sources. However, the growth of demand for clean, reliable and affordable electricity generation is changing this existing scenario. On the other hand, the aging centralized energy infrastructure, which can be more vulnerable with the increasing power demand, requires innovative and economical solutions as the construction of new transmission facilities is highly constrained by the environmental considerations. Many goyernments in the world have responded to these demands with suitable policy adjustments that encourage distributed and renewable energy generation. As a result, the share of renewable and efficient DGs is rapidly increasing. For example [7] reports that in Canada, as of 2005, 25\% of new electricity generation installed has come from distributed resources, compared to only $13 \%$ in 2002 .

\subsection{Energy Storage Devices}

Energy storage devices are one of the main critical components to rely on for successful operation of a microgrid. The main function of the energy storage devices in a microgrid application is to be the care taker in balancing the power and energy demand with generation. Energy storage devices take this responsibility in three necessary scenarios.

1. Insure the power balance in a microgrid despite load fluctuations and transients as DGs with their lower inertia lack the capability in fast responding to these disturbances.

2. Provides ride-through capability when there are dynamic variations in intermittent energy sources and allows the DGs to operate as dispatchable units.

3. Provides the initial energy requirement for a seamless transition between grid-connected to/from islanded operation of microgrids.
Among the available energy storage technologies [8], [9], batteries, fly-wheels and supercapacitors are more applicable for microgrid type of setup [10]. In the use of a flywheel, it can be used as a central storage system for the whole microgrid. In the use of batteries, either storage can be mounted on the dc bus of each micro-source or can be used as a central storage system. Batteries provide extra function being able to reserve energy for future demand. Super capacitors would be an expensive choice compared to both batteries and flywheels [8]. Another option is to have a large traditional generation having considerable inertia along with the micro-sources.

\subsection{Interfacing Distributed Energy Resources (DER)}

Distributed energy resources (DER) refer to both DG and energy storage technologies. Most of the emerging DER technologies require an inverter interface in order to convert the energy into gridcompatible ac power. This interfacing may either consist of both converter and inverter or only an inverter. The power electronic interface will be accommodated with filters and necessary protection systems. With the converter's capability of voltage and frequency control, these DER units support the microgrid operation. Table 1 summarizes the interfacing and power flow control options of common DER

\subsection{Microgrid Loads}

A microgrid could serve variety of customers: residential, commercial and industrial. In general, commercial and industrial users are defined as critical/sensitive loads, which demand high degree of power quality and reliability. This classification of loads is important in the microgrid setup to achieve the expected operating strategy:

1. Facilitate load/generation shedding within the microgrid to meet the net import/export power in grid connected mode.

2. Facilitate load/generation shedding to stabilize the voltage and frequency in the autonomous operation.

3. Improve the power quality and reliability of critical and sensitive loads.

4. Reduces the peak load to optimize the ratings of DER.

Part of the non-sensitive loads can be used as controllable loads to achieve the above operating strategies in a microgrid [11], [13]. 
International Journal of Trend in Scientific Research and Development (IJTSRD) ISSN: 2456-6470

Table 1. Typical Interfaces Used With DER

\begin{tabular}{|c|c|c|c|}
\hline $\begin{array}{l}\text { Primary energy } \\
\text { source type }\end{array}$ & Typical interface & Power flow control & Primary energy source type \\
\hline \multirow[t]{6}{*}{$\mathrm{DG}$} & $\mathrm{CHP}$ & Synchronous generator & AVR and Governor $(+\mathrm{P}, \pm \mathrm{Q})$ \\
\hline & $\begin{array}{l}\text { Fixed speed wind } \\
\text { turbine }\end{array}$ & Induction generator & $\begin{array}{c}\text { Stall or pitch control of turbine }(+\mathrm{P}, \\
-\mathrm{Q})\end{array}$ \\
\hline & $\begin{array}{l}\text { Variable speed } \\
\text { wind turbine }\end{array}$ & $\begin{array}{l}\text { Power electronic converter } \\
(\mathrm{AC}-\mathrm{DC}-\mathrm{AC})\end{array}$ & $\begin{array}{c}\text { Turbine speed and DC link voltage } \\
\text { controls }(+\mathrm{P}, \pm \mathrm{Q})\end{array}$ \\
\hline & Micro-turbine & $\begin{array}{l}\text { Power electronic converter } \\
(\mathrm{AC}-\mathrm{DC}-\mathrm{AC})\end{array}$ & \\
\hline & Photovoltaic (PV) & $\begin{array}{l}\text { Power electronic converter } \\
(\mathrm{DC}-\mathrm{DC}-\mathrm{AC})\end{array}$ & $\begin{array}{l}\text { Maximum power point tracking and } \\
\text { DC link voltage controls }(+\mathrm{P}, \pm \mathrm{Q})\end{array}$ \\
\hline & Fuel cell & $\begin{array}{l}\text { Power electronic converter } \\
\text { (DC-DC-AC) }\end{array}$ & \\
\hline \multirow[t]{3}{*}{ Energy storage } & Battery & $\begin{array}{c}\text { Power electronic converter } \\
(\mathrm{DC}-\mathrm{DC}-\mathrm{AC})\end{array}$ & $\begin{array}{c}\text { State of charge and output } \\
\text { voltage/frequency control }( \pm \mathrm{P}, \pm \mathrm{Q})\end{array}$ \\
\hline & Fly-wheel & $\begin{array}{c}\text { Power electronic converter } \\
(\mathrm{AC}-\mathrm{DC}-\mathrm{AC})\end{array}$ & Fly-wheel \\
\hline & Super capacitor & $\begin{array}{l}\text { Power electronic converter } \\
\text { (DC-DC-AC) }\end{array}$ & State of charge $( \pm \mathrm{P}, \pm \mathrm{Q})$ \\
\hline
\end{tabular}

\subsection{Interconnection of Microgrids}

Microgrids get connected to the power system at the distribution level. Also, energy handling capability of microgrids is limited with the use of renewable energy resources and waste heat. Thus, maximum capacity of a microgrid is normally restricted to 10MVA [2].

Microgrid is connected to the utility system via an interconnection switch. If the microgrid consists of voltage-sensitive loads such as semiconductor manufacturing, it requires separation times of less than $50 \mathrm{~ms}$ [2]. However, the existing protective equipment and circuit breakers are not capable to act that fast to isolate and change the mode of control in the microgrid. In such a condition it is required to maintain the voltage above $50 \%$ of the rating at any time of operation [2].

Consequently, the recent research has applied static switches with fast response or Digital Signal Processor (DSP) based switches that consolidate both power switching and relaying, as the interconnection method [14], [15].

\subsection{Control and Communication Strategies Used}

The main advantage expected from a microgrid is that it should allow to be treated as a controlled aggregated load within the power system. Also, being in the vicinity of smart grid systems, microgrids should facilitate adaptive control approaches.
The present research in microgrids adopts control approaches that could be imbedded as autonomous parts of each distributed generator, use a central controller or based on agents. Autonomous control allows placing additional DGs without reengineering the system, and using it in the peer-to-peer model (using $(N+1)$ DERs in the system) eliminates the requirement of a complex central controller and associated telecommunication facilities. The agent based system facilitates both centralized co-ordination and local control as it operates in different levels as a hierarchy. This approach allows utilization of the strengths of both central and decentralized control systems and this is a possible candidate for future smart grid approaches.

Communication can be one of the most vital elements in a microgrid, particularly for power control and protection. The basic communication methods used so far include: radio communication, leased telephone lines, power-line carrier, internet and Global System for Mobile (GSM) Communications. The present microgrid experiments have used different communication protocols, but establishment of some standard communication protocol could help reduce costs and accelerate the deployment of microgrids. 


\section{Experimental Microgrids and Microgrid Test- Beds}

Microgrid is a subject that has been studying and testing around the world in the recent past. The thriving interest on microgrids is reflected by the forthcoming IEEE Std P1547.4 on Guide for Design, Operation, and Integration of Distributed Resource Island Systems with Electric Power [16] which is specifically developed to address the missing information in IEEE Std 1547-2008 [17] regarding intentional islands.

There is no particularly accepted benchmark test system for microgrids. The research works on microgrids are based on either test-beds or simulations using different microgrid topologies. There are some typical microgrid configurations also reported. In this section, it is attempted to summarize the microgrid test systems reported in the literature.

\section{Intentional Islanding and Microgrid Experience around the World}

\subsubsection{Boston Bar - BC Hydro, Canada}

The BC Hydro Boston Bar is a microgrid that is interconnected to $69 \mathrm{kV}$ feeders through a $69 / 25 \mathrm{kV}$ substation comprising of three radial feeders. It was built as a solution to the frequent experiencing power outages between 12 and $20 \mathrm{~h}$ periods that happens due to permanent outages on the $69 \mathrm{kV}$ line connecting the substation to the $\mathrm{BC}$ Hydro grid.

Fig. 1 presents the single-line diagram of the Boston Bar system [10], [18]. The microgrid comprises of two 4.32 MVA run-of-river hydro power generators connected to one feeder. The peak load of the microgrid is $3 \mathrm{MW}$ and depending on the demand and water level, it supplies power to one or more feeders by sectionalizing loads accordingly.

The system is not equipped with a storage unit, but the inertia of the generators has increased purposely. A leased telephone line is used for communication. The controlling options include:

1. Generators operate in isochronous mode in single generator operation and governor speed-droop control is used in parallel operation.

2. Transient response is improved by engineering mass of generators and hydro turbines, thus increasing inertia.
3. Automatic voltage regulation (AVR) control is used to regulate voltages at the Point of Common Coupling (PCC).

4. Two sets of over current protection set-points for the grid-connected and the islanding operating modes.

5. To supply high fault current during a feeder fault, the excitation system control is made with positive voltage field forcing for output current boost.

6. When the island happens substation breaker open position is telemetered via leased telephone line between the generator(s) remote control site and the utility Area Control Centre.

7. Black start capability is provided via an on-site 55 $\mathrm{kW}$ diesel generator if the generator(s) fail to sustain the island.

8. Remote auto-synchronization capability is added at the substation level to synchronize and reconnect the island area to the $69 \mathrm{kV}$ feeders without causing load interruption.

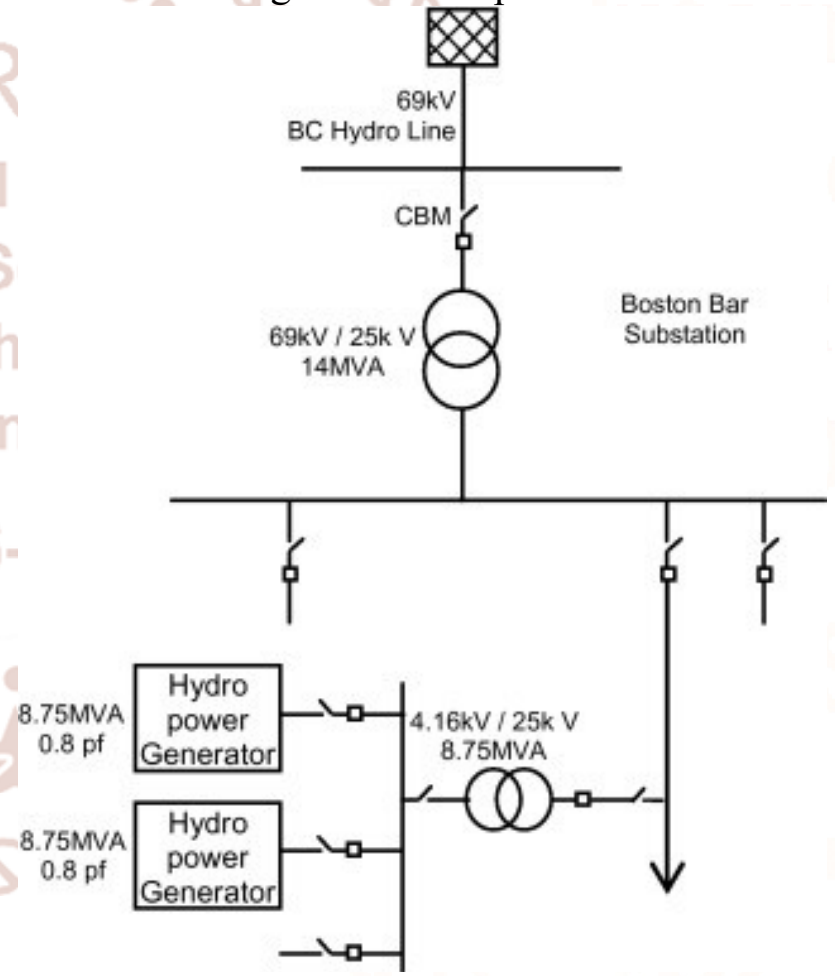

Fig. 1. Single-line diagram of the BC Hydro Boston Bar system

\subsubsection{Boralex planned islanding - Hydro Quebec (HQ), Canada}

The substation named Senneterre in Quebec feeds three distribution lines, serving 3000 customers. The substation is supplied at $120 \mathrm{kV}$ by a $40 \mathrm{~km}$ long transmission line which had required an urgent replacement. The Boralex thermal power plant is connected through the Senneterre substation to the HQ Network. Thus, the restoration of the transmission 
line has done by using the Boralex power plant for islanding of HQ's Senneterre substation. The generator has shown stable operation in isochronous mode under varying loads. The peak load tested was around $7 \mathrm{MW}$. Fig. 2 presents the planned islanding with Boralex plant at the Senneterre Substation [18].

Since this system is operated with a single, comparatively large generator and operated as an island only during the planned system maintenance, it does not use any storage or communication system.

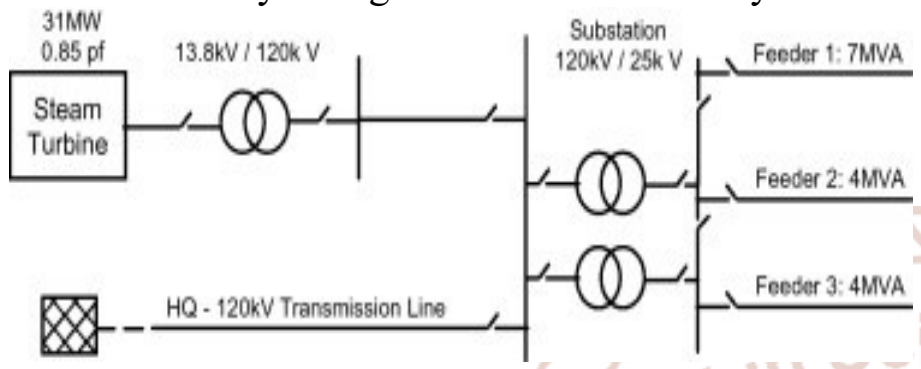

Fig. 2. Planned islanding with Boralex plant at Senneterre Substation.

\section{Conclusions}

Microgrids are likely to play a key role in the evolution of smart-grids. They could become prototypes for smart-grid sites of the future.

There are many variations in adopting the microgrid architecture and design. However, they are implemented with common perspectives such as reliability and optimal integration of DGs. With the present experience, identifying the dependable control strategies and utilizing them accordingly to further improve the system reliability is a key requirement.'

It is important to research in more reliable, fast responding islanding detection method that would be simple in integrating to a microgrid. It is also important to study the critical transition period (from grid connected mode to islanded operation mode) for stable operation of a microgrid. The survey reveals conventional controlling methods are always used in microgrid implementations. Thus, development of a generic simulation model that would reflect the properties of the present microgrids would facilitate further research in transient stability performance, protection and control strategies and development of design guidelines standards for microgrids.

\section{REFERENCES}

1. enkins N, Allan R, Crossley P, Kirschen D, Strbac G. Embedded generation, IEE power and energy series 13. London: IET; 2000.
2. Chowdhury S, Chowdhury S P, Crossley P. Microgrids and active distribution networks, IET renewable energy series 6. London: IET; 2009

3. Pepermansa G, Driesenb J, Haeseldonckxc D, Belmansc R, D'haeseleer W. Distributed generation: definitions, benefits and issues. Energy Policy 2005; 33(18):787-98.

4. Zareipour H, Bhattacharya K, Canizares C A. Distributed generation: current status and challenges. In: Proceedings of the 36th annual North American power symposium; 2004.

5. Venkataramanan G, Marnay C. A large role for microgrids: are microgrids a viable paradigm for electricity supply expansion? IEEE Power Energy Magazine 2008; May/June:78-82.

6. Lasseter, R, Akhil, A, Marnay, C, Stephens, J, Dagle, J, Guttromson, R, Meliopoulous, A S, Yinger, R, Eto, J. The CERTS microgrid concept, White paper on Integration of Distributed Energy Resources. CERTS, Canada, Consultant Report no. P500-03-089F, October 2003.

7. Doukas A. Distributed generation in Canadamaximizing the benefits of renewable resource; promoting a transition to renewable energy. Canadian Renewable Energy Alliance; August 2006.

8. Sels T, Dragu C, Van Craenenbroeck T, Belmans R. Electrical energy storage systems: existing systems versus newest systems - an overview. In: Power generation and sustainable development international conference. 2001.p. 215-20.

9. E. A. Technology. Review of Electrical Energy Storage Technologies and Systems and of their Potential for the UK. DTI 2004. URN 04/1876.

10. Kroposki B, Lasseter R, Ise $\mathrm{T}$, Morozumi S, Papatlianassiou S, Hatziargyriou N. A look at microgrid technologies and testing projects from around the world, Making microgrids work. IEEE Power Energy Magazine 2008; May/June:40-53.

11. Katiraei F, Iravani R, Hatziargyriou N, Dimeas A. Microgrids management: controls and operation aspects of microgrids. IEEE Power Energy Magazine 2008; May/June:54-65.

12. DTI. Micro-generation strategy and low carbon buildings programme- consultation. Available on 23 June 2005. http://www.dti.gov.uk/files/ file13989.pdf.

13. Driesen J, Katiraei F. Design for distributed energy resources. IEEE Power Energy Magazine 2008;(May/June):30-40. 